This report was prepared as an account of work sponsored by an agency of the United States Government. Neither the United States Government nor any agency thereof, nor any of their employees, makes any warranty, express or implied, or assumes any legal liability or responsibility for the accuracy, completeness, or usefulness process disclosed, or represents that its use would not infringe privately owned rights. Reference herein to any specific commercial product, process, or service by trade name, trademark, manufacturer, or otherwise does not necessarily constitute or imply its endorsement, recommendation, or favoring by the United States Government or any agency thereof. The views and opinions of authors expressed herein do not necessarily state or reflect those of the

United States Government or any agency thereof.

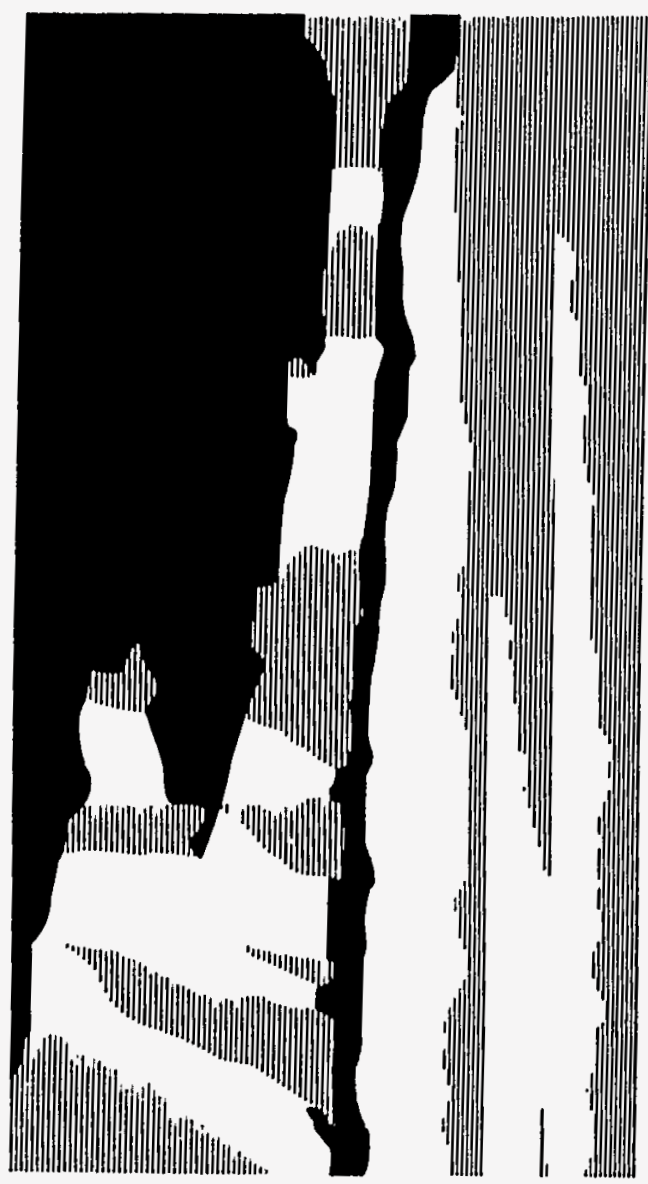

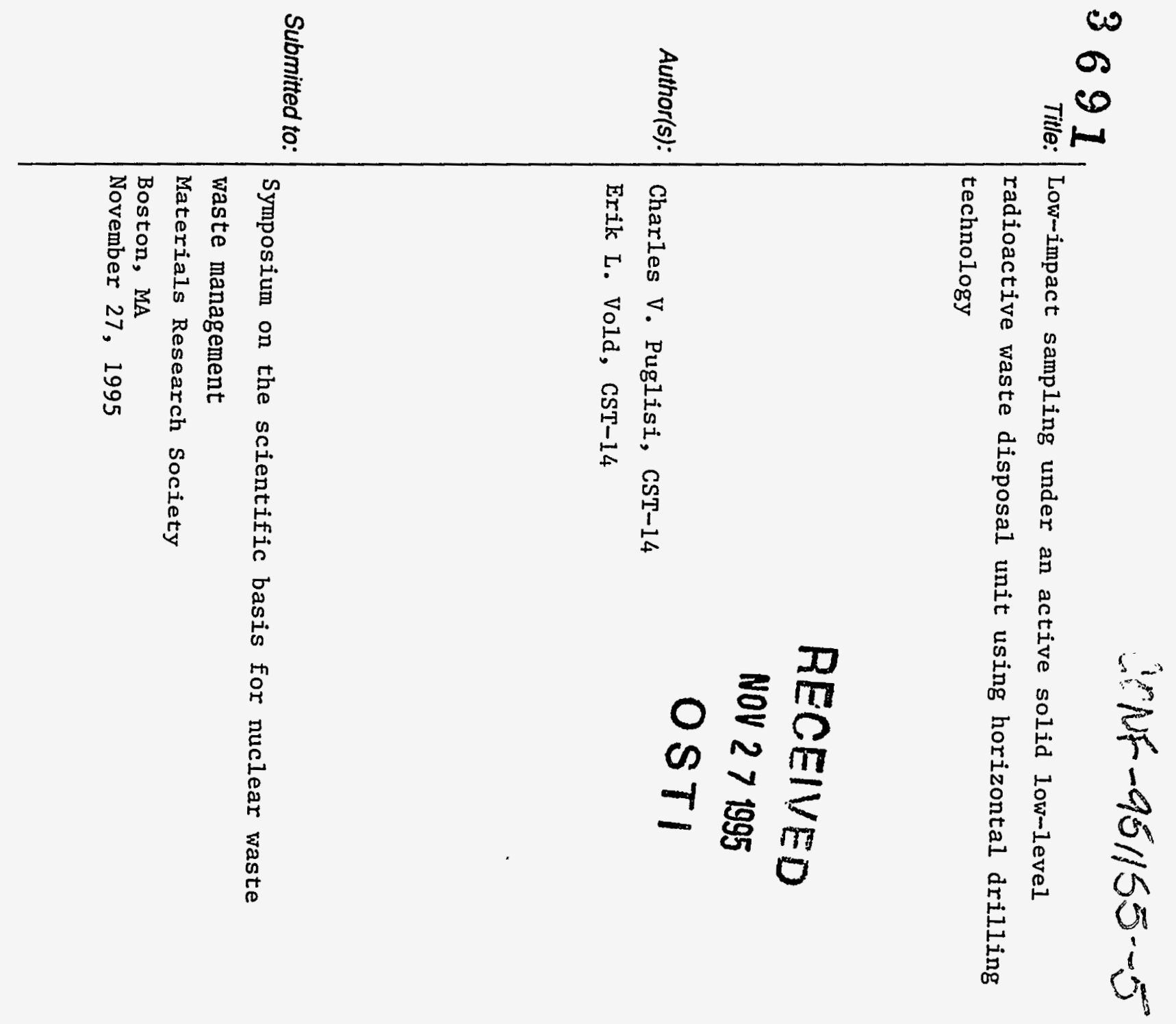




\section{DISCLAIMER}

Portions of this document may be illegible in electronic image products. Images are produced from the best available original document. 


\title{
LOW-IMPACT SAMPLING UNDER AN ACTIVE SOLID LOW-LEVEL RADIOACTIVE WASTE DISPOSAL UNIT USING HORIZONTAL DRILLING TECHNOLOGY
}

\author{
C. V. Puglisi, E. L. Vold
}

Chemical Science and Technology Division (CST), Los Alamos National Laboratory, 1663 Los Alamos, NM 87545, cvp@lanl.gov, elv@lanl.gov

\section{ABSTRACT}

The purpose of this project was to determine the performance of the solid low-level radioactive waste (LLRW) disposal units located on a mesa top at TA-54, Area G, Los Alamos National Laboratory (LANL), Los Alamos, NM, and to provide in-situ (vadose zone) site characterization information to Area G's Performance Assessment. The vadose zone beneath an active disposal unit (DU 37), was accessed by utilizing low-impact, air-rotary horizontal drilling technology. Core samples were pulled, via wire-line core method, in 3 horizontal holes fanning out below DU 37 at approximately 5 foot intervals depending on recovery percentage. Samples were surveyed and prepared in-field following Environmental Restoration (ER) guidelines. Samples were transferred from the field to the CST-9 Radvan for initial radiological screening. Following screening, samples were delivered to CST-3 analytical lab for analyses including moisture content, 23 inorganics, 60 volatile organic compounds (VOC's), 68 semivolatile organic compounds (SVOC's), tritium, lead 210, radium $226 \& 228$, cesium 137, isotopic plutonium, americium 241, strontium 90, isotopic uranium, and isotopic thorium. Other analyses included matric potential, alpha spectroscopy, gamma spectroscopy, and gross alpha/beta. The overall results of the analysis identified only tritium as having migrated from the DU. Am-241, Eu-152, and $\mathrm{Pu}-238$ were possibly identified above background but the results are not definitive. Of all organics analysed for, only ethyl acetate was tentatively identified slightly above background. All inorganics were found to be well below regulatory limits. Based on the results of the above mentioned analyses, it was determined that Area G's disposal units are performing well and no significant liquid phase migration of contaminants has occurred.

\section{INTRODUCTION}

The purpose of this project was to determine the performance of the solid LLRW disposal units, and to characterize the vadose zone beneath those units, located at TA-54, Area G. Some of the information gathered will be used in Area G's Performance Assessment which is the technical basis for solid LLRW disposal at Area G. TA-54, Area G, LANL is located in the northern part of the state approximately $60 \mathrm{~km}(100 \mathrm{mi})$ northwest of Albuquerque, NM. Department of Energy (DOE) Orders 5820.2A, 5400.1 and 5400.5 outline the requirements for environmental monitoring and surveillance of a DOE managed nuclear facility. The project followed DOE ER guidelines for drilling and sampling. $\{R E F\}$ ?

Area $G$ is located on top of a finger mesa that is part of a series of mesas created by volcanic activity approximately 1.2 million years ago. The mesas consist of layered, fractured volcanic ash (tuff) flows that run in an easterly direction toward the Rio Grande. The drilling took place in layers $2 a$ and $1 b$ of the Bandelier tuff and started at approximately 70 feet below grade. The distance to the water table from the bottom of the disposal units is approximately $700-900 \mathrm{ft} .\{\mathrm{REF}\}$ ? 
Duration of the project was approximately 6 weeks running from 1/25/95 through $3 / 10 / 95$. Weather conditions during the project were typical for that time of year running from moderate, clear, to below freezing, snowy days and nights. The drill site (see Figure 1), located within a Radiological Control Area, was situated at the bottom of a newly excavated disposal unit, DU 38, in a drilling trench (see Figure 2) adjacent to the bottom of DU 37. Due to the location of the drill site an air-rotary drilling method was used in lieu of normal drilling methods to eliminate the slurry waste associated with such methods.

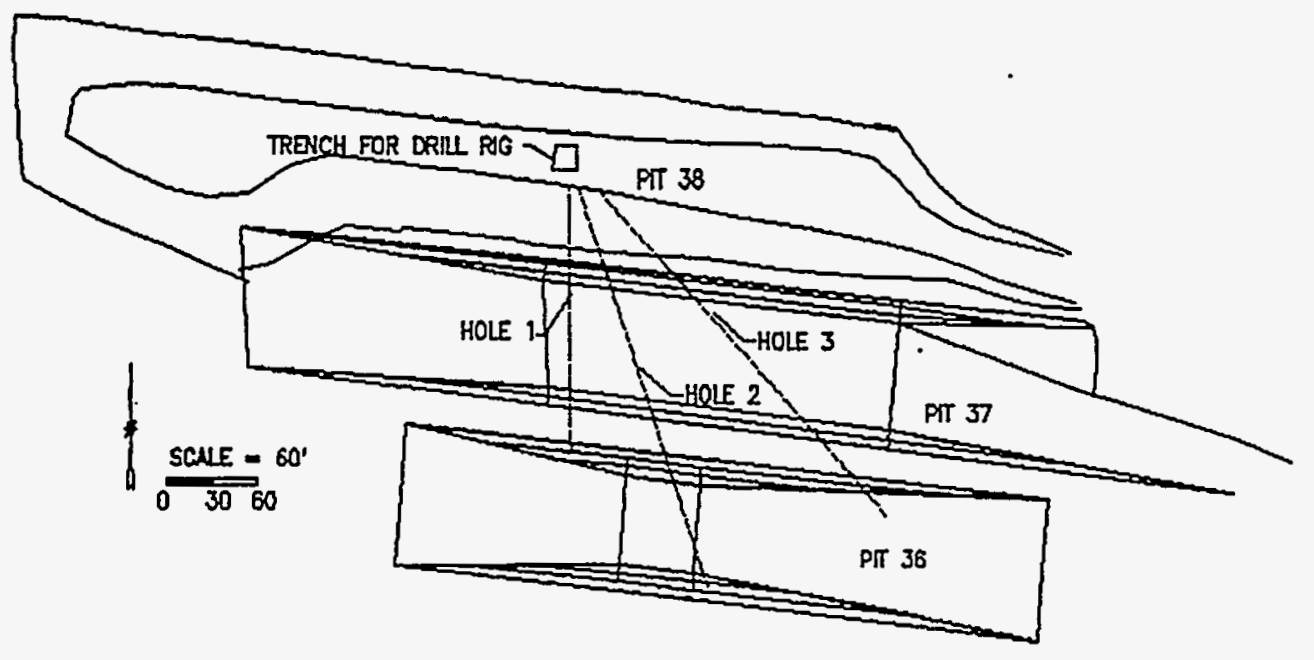

Figure 1. Plan view of the site. The drill rig was situated in DU 38 and the three horizontal bore holes radiated out from that location.

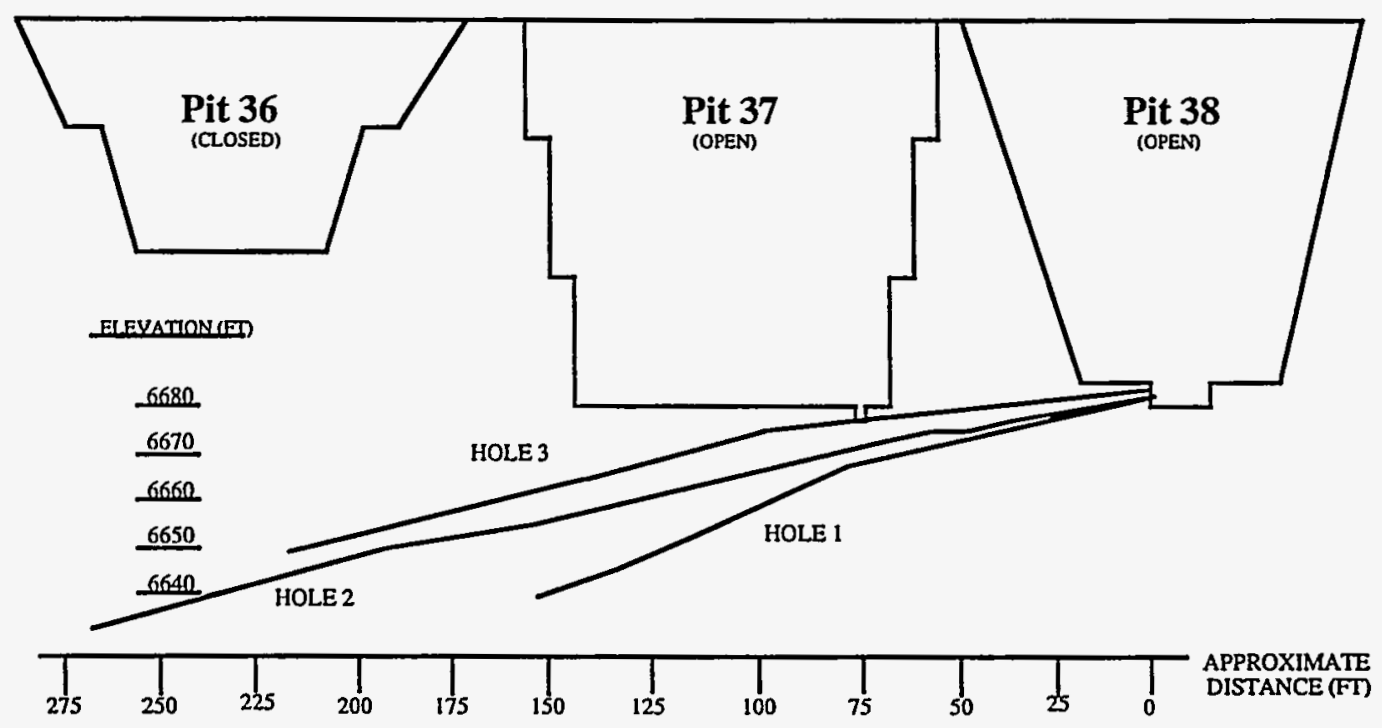

Figure 2. Cross section view of boreholes $1(151 \mathrm{ft}), 2(240 \mathrm{ft})$, and $3(267 \mathrm{ft})$ beneath Disposal Units 36, 37, and 38.

\section{METHOD}

\section{Drilling}

Drilling was performed using a air-rotary Long-year 44 diesel powered core drilling rig. The rig was situated in a $16^{\prime} \times 16^{\prime} \times 4^{\prime}$ deep trench in the bottom of DU 38 so as to allow better horizontal access beneath DU 37 (see Figure 2). The steel core drilling barrel had an outer 
diameter of 4.5 inches and was loaded in 10 foot lengths. Core cuttings were removed by a vacuum trailer consisting of a three cyclone, fully enclosed, dust removal system. This allowed access around the drill site without having to use any respiratory protection. Three horizontal bore holes were drilled in a southerly direction from DU 38 in a web-like pattern enabling us to cover a representative portion of the vadose zone directly beneath DU 37 without having to relocate the drill rig for each new hole (see Figure 1). The combination of the air-rotary method and web-like drilling pattern saved considerable downtime thereby saving cost. Each hole was sampled for characterization (matric potential and moisture content) and contaminant migration (see Table 1). Upon completion of drilling, the holes were sealed for future monitoring access and the drilling trench was filled in with the original excavated material.

The core removed from these stratographic units consisted of approximately $25-50 \%$ devitrified pumice $(0.1-6.0 \mathrm{~cm}), 1-10 \%$ semi-angular grey and black lithics $(0.1-3.0 \mathrm{~cm}), 1-5 \%$ phenocrys $(>0.1 \mathrm{~cm})$, and $20-50 \%$ ash. The tuff's degree of weldedness ranged from $1-4$ where 1 is non-welded (sugar-like texture) and 4 is welded (brick-like texture). The color of the tuff was mostly grey with some brown probably due to organic matter infiltrating the fractures.

\section{Sampling}

In-situ core sampling was performed by taking core samples at approximately $5 \mathrm{ft}$ intervals throughout each hole using a wire-line core split spoon method. All runs and sample screenings were performed with a Ludlum 139 alpha monitor and a Eberline ESP1 beta monitor and followed DOE ER procedures. All runs and samples were cleared for handling. Core samples had an outer diameter of 2.5 inches. Stainless steel tubes ( 6 inch) were used for organic samples and lexan tubes (6 inch) were used for inorganic and isotopic samples. Plastic baggies were used for matric potential samples. The remaining core was recorded and labeled following DOE ER guidlines and stored at LANL's Sample Management Facility.

\section{Analysis}

Table 1 is a list of the number of core samples and the analyses performed for each hole. For organic analysis gas chromatography mass spectometry was the method used. For inorganic analysis inductively coupled plasma mass spectometry, inductively coupled plasma emission spectometry, electrothermal vaporization atomic absorbtion, and cold vapor atomic absorbtion were the methods used. Chilled Mirror Psychrometry and gravimetric analysis were the methods used for matric potential and moisture content respectively. Table 2 is a breakdown of the radiological screening. Methods used included liquid scintillation, proportional counting, alpha spectroscopy, gamma spectroscopy, and gross alpha/beta.

Table 1. Core Sample Analyses

\begin{tabular}{|l|c|c|c|c|c|c|}
\hline & 60 VOC's & 68 SVOC's & 23 Inorganics & Radiologic & Matric Potential & Moisture \% \\
\hline Hole 1 & 8 & 8 & 7 & 7 & 63 & 7 \\
Hole 2 & 9 & 9 & 12 & 12 & 60 & 7 \\
Hole 3 & 10 & 10 & 11 & 11 & 55 & 7 \\
\hline
\end{tabular}


Table 2. Radiological Analytes Screened

\begin{tabular}{|c|c|c|c|c|c|}
\hline Analyte & Analyte & Analyte & Analyte & Analyte & Analyte \\
\hline $\mathrm{H} 3$ & $\mathrm{~Pb}-210$ & Th-234 & $\mathrm{U}-234$ & isotopic Pu & $\mathrm{Pu}-240$ \\
$\mathrm{Sr}-90$ & $\mathrm{Ra}-226$ & Am-241 & $\mathrm{U}-235$ & Pu-238 & \\
$\mathrm{Cs}-137$ & isotopic Th & isotopic U & $\mathrm{U}-238$ & $\mathrm{Pu}-239$ & \\
\hline
\end{tabular}

\section{RESULTS}

Table 3 is a summation of the analytical results of the core samples that showed up as slightly above or above background. All other analytical results were reported as either background, below background, or undetectable levels, therefore it was not relevant to publish them in this report. Following Table 3 are explanations given as the most plausible reasons for detection.

Table 3. Results

\begin{tabular}{|c|c|c|}
\hline Analysis & Detection & Possible Detection \\
\hline Organic(VOC) & 0 & Ethyl Acetate \\
Organic(SVOC) & 0 & 1 Unknown \\
Inorganic & 0 & 0 \\
Radiologic & $\mathrm{H} 3$ & Eu152, Am241, Pu238 \\
Moisture \% & normal(2-10) & \\
\hline
\end{tabular}

\section{Organics}

The SVOC detected was an unknown and in such low concentrations that it is not a concern. The one VOC (Ethyl Acetate) that was only tentatively identified, was also in such a small amount (ppb) that it also is not a concern. Because of the uncertainty of these results it is likely that the possible detection came from either lab counting error or contamination from actual drilling operations.

Inorganics

Of the 23 metals analyzed for, all were detected at background levels and are well below RCRA regulatory limits.

\section{Moisture}

The moisture concentrations in the core samples are consistent with in-situ background levels for the disposal facility. [1] The moisture content and water activity results for core samples recovered as a function of distance into horizontal borehole \#2 are shown in Figure 3. Moisture content starts in the range $1-2 \%$ as is often seen below a depth of $30^{\prime}$ from the mesa surface [1]. The moisture increases significantly with distance which corresponds to a slight drop in elevation as the boreholes dip below the nominal horizontal position as seen in Fig. \#2. The final moisture values near $10 \%$ gravimetric content are somewhat high at this depth for an undisurbed location but within the range seen as one approaches the depth of the vapor phase notch at the interface between stratigraphic units $1 \mathrm{~b}$ and $1 \mathrm{a}$. The boreholes may be approaching this stratigraphic feature or there is a possibility that disposal operations have influenced the water content at these locations by unsaturated transport from the DU bottoms. 


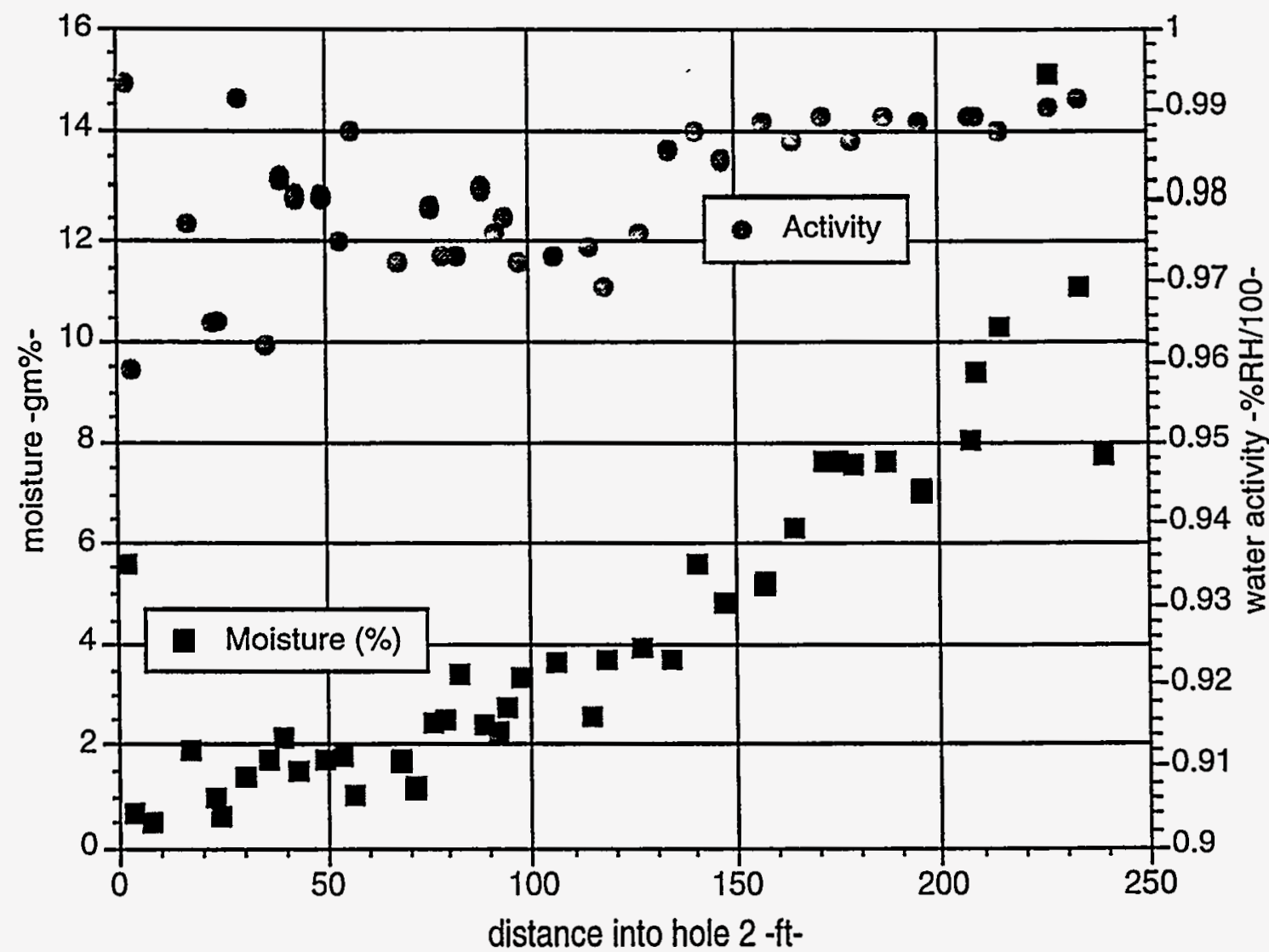

Figure 3. Moisture content and water activity measurements on recovered core samples as a function of distance into horizontal borehole \#2.

This warrents further study to determine if the observed moisture content is attributable to disposal operations.

The water activity (relative humidity expressed as a fraction) is measured on core samples carefully packaged in-field and then crushed for analysis on a commercially available water activity meter [ref??]. As moisture content increases, the activity is seen to increase slowly as shown in Figure 3.

The water activity is directly converted to a matric head assuming that the osmotic head is negligible. These results are seen in Figure 4, where the figure labels are as follows: $-\mathrm{hm}(\mathrm{A})$, the matric head directly converted from the water activity readings, -hm(vG\#), matric head calculated from the moisture content data, using van Genuchten fitting parameters [2] derived for Bandelier Tuff, Unit \#, where \# is the stratigraphic unit designator, $2 b, 2 a, 1 b$, or 1a, common in the hydrologic literature describing the area. The average van Genuchten fit parameters for each unit were used [3]. At Area G, Unit $2 b$ is the uppermost stratigraphic layer descending through the $2 \mathrm{~b}-2 \mathrm{a}$ interface at a depth of about 40', 2a-1b at about 60-70' depth and $1 \mathrm{~b}-1 \mathrm{a}$ at about $100^{\prime}$ depth. The depth of the drilling project is about $70^{\prime}$ from the mesa top.

It was assumed that the matric head from the water activity would correlate well with the matric values calculated using the moisture content for one or another of the stratigraphic unit parameters expected at these locations. The data is seen to be in rough agreement at distances less than $100^{\prime}$ where the moisture content is small, $<4 \%$, with $\mathrm{hm}(\mathrm{A})$ agreeing best with the values calculated using unit $1 \mathrm{~b}$ van Genuchten parameters. As the distance increases beyond 100', the moisture content increases and the predicted matric heads drop continuously by an order of magnitude while the matric head derived from the water activity readings decreases only slightly. 


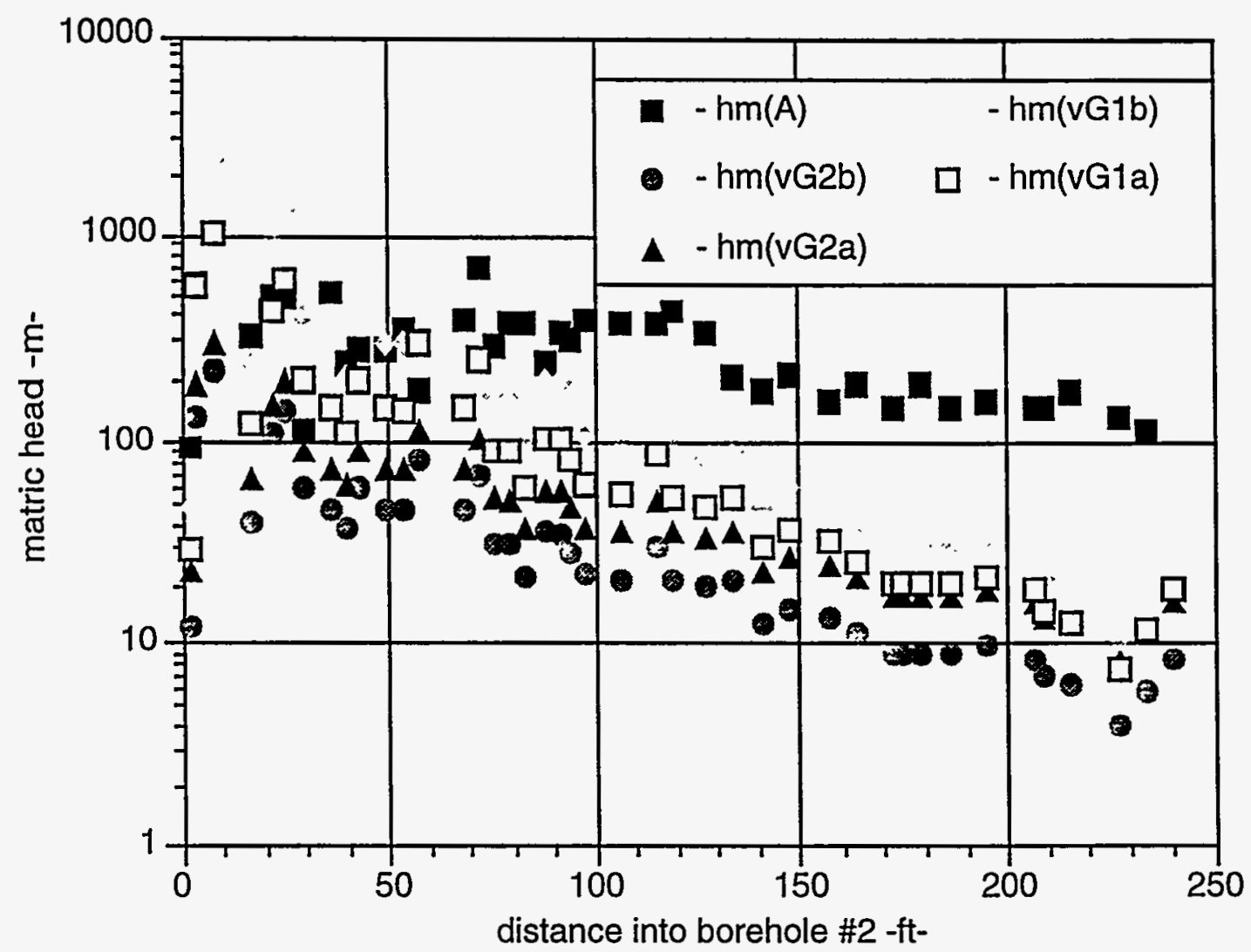

Figure 4. Matric head $\left(\mathrm{h}_{\mathrm{m}}\right)$ as a function of distance into horizontal borehole \#2, determined by sample water activity - $\mathrm{hm}(\mathrm{A})$, and by sample moisture content with empirical fits for the matric head as a function of moisture content. Results using fit parameters for each of the 4 stratigraphic units in the Area $G$ mesa are shown.

The source of this apparent discrepency is under continuing investigation. One possibility is that the samples for the activity meter dried out before measurements were complete, possibly during the air-core drilling. This would tend to predict a higher matric potential, but drying during drilling would have reduced the moisture content data, too. The depth to the water table is about $250-300 \mathrm{~m}$, so the matric potential from the water activity appears to be consistent with moisture contents in static equilibrium above this water table. Conversely, the matric heads derived from the moisture content with the van Genuchten fitting parameters are less than the static head required at this elevation, suggesting non-static conditions.

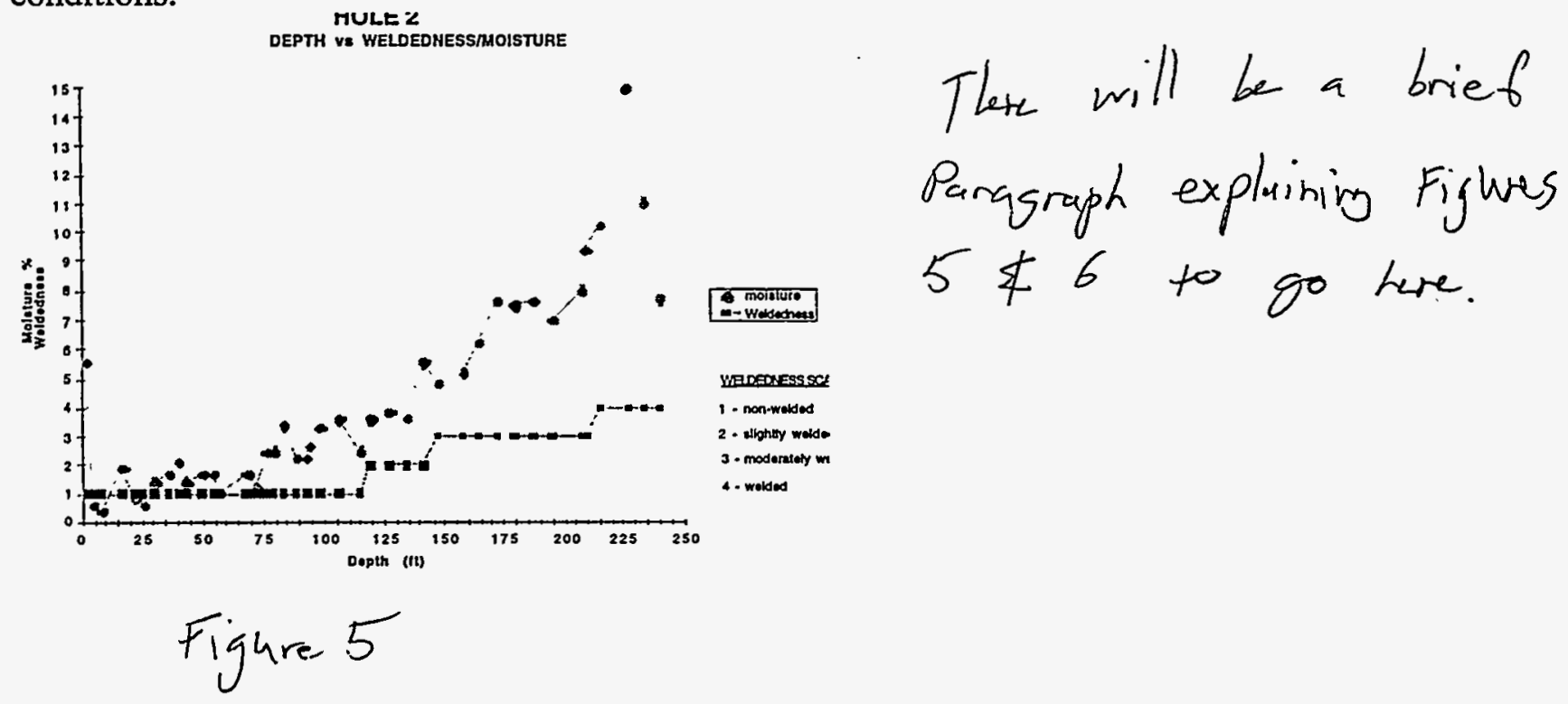




\section{FIGURE 6}

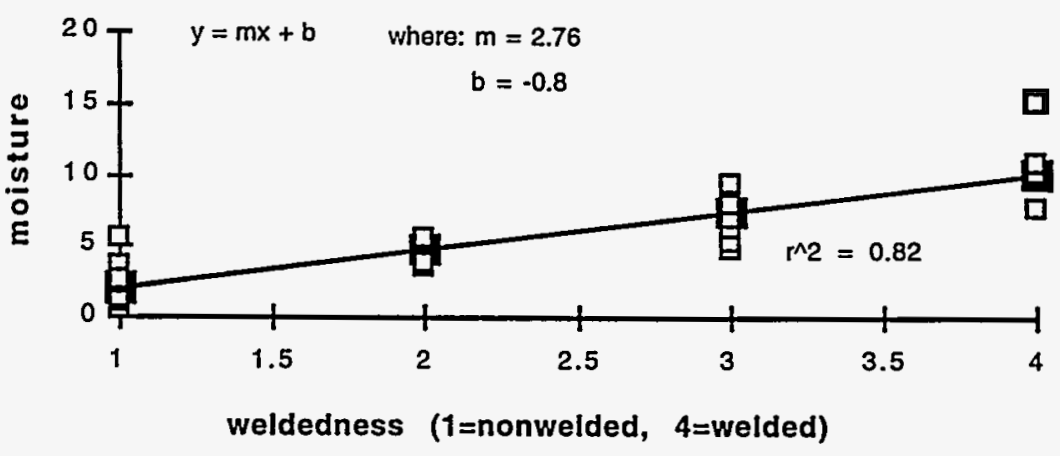

Figure 6 shows the linear regression between the degree of weldedness of the tuff and the moisture content of the tuff.

\section{Isotopic}

H3 - core samples in each hole that were above background levels. DU 37 inventory is about $12 \mathrm{Ci}$ of tritium. If we assume this was deposited in a single $1 \mathrm{~m} 3$ package the dilution to the location of the plume maximum is about $5 \mathrm{e}-6$. If we assume the tritium was deposited in several packages distributed throughout half the volume of DU 37 ( $2 \mathrm{e} 4 \mathrm{~m} 3)$, the disposal pit average concentration is about $4 \mathrm{e}-4 \mathrm{Ci} / \mathrm{m} 3$, or a dilution to the plume point of 0.1 . These two assumed cases bound the possible range and either produces a plausible result. Since the tritium moves in the vapor phase it is not indicative of any other radioactive contaminant. Since Area $G$ has other minor $\mathrm{H} 3$ plumes this was to be expected. samples:

The following results are for three isotopes that might possibly be present in the

Am-241 - there may be a limited number of samples which are marginally above background levels. Analyses seemed to indicate 2-3 core samples per hole with mean values slightly above the analytic uncertainty levels (reported mean of 2-3 times the one sigma analytic uncertainty), with the reported mean value above surface soil background levels. \{REF Conrad\} There was some inconsistency between data from two different analytic labs and their respective uncertainty levels.

Eu-152 - in the gamma scan this nuclide was detected marginally above counting background in almost every sample with a mean in the range $0.2-0.5 \mathrm{pCi} / \mathrm{gm}$, and analytic uncertainty in the range $<0.1$. The ubiquitous nature of this observation suggests consistent counting error or a nearly uniform background possibly due to fallout residual.

Pu-238 - 1 hit at about 3 times background (REF Conrad) and 3 hits at about 2 times background, in hole 3 shows this may be significant. Additional statistical tests may be appropriate.

These results are based on a preliminary review and identify all analyzed nuclides which are possibly elevated above detection or background levels. Except for tritium, which is clearly elevated, each of the contaminants identified as possibly greater than background are only 
marginally so, and require additional inquiry and/or statistical analysis to verify whether or not the levels actually exceed background.

\section{CONCLUSIONS}

Area G's disposal facility is situated within units $2 b, 2 a$ and $1 b$ of the Bandelier tuff. Since the drilling project took place in units $2 \mathrm{~b}$ and $1 \mathrm{a}$, and given the geological homogeneity of these units, we can assume the results apply throughout the site. Therefore, based on the results of the analysis, we are confident that all of Area G's disposal units are performing similarly to DU 37. No liquid phase migration to the vadose zone has occurred. What little movement has occurred is most likely attributable to vapor phase movement.

\section{REFERENCES}

[1]- D. Loaiza and E. Vold, Moisture Profile Measurements in Subsurface Monitor Holes at the Los Alamos LLRW Disposal Site, Los Alamos National Laboratory Report LAUR-95-1922, Los Alamos, NM, submitted to the Journal, Environmental Monitoring, June, 1995.

[2]- D. Krier, P. Longmire, R. Gilkeson, H.J.Turin, "Geologic, Geohydrologic, and Geochemical Data Summary of MDA G, TA-54, LANL", Los Alamos National Laboratory Report LA-UR-95-2696, Los Alamos, NM, 1995.

[3]- M. Th. van Genuchten, A Closed-form Equation for Predicting the Hydraulic Conductivity of Unsaturated Soils, Soil Science Society of America Journal, 44, 892-898, 1980.

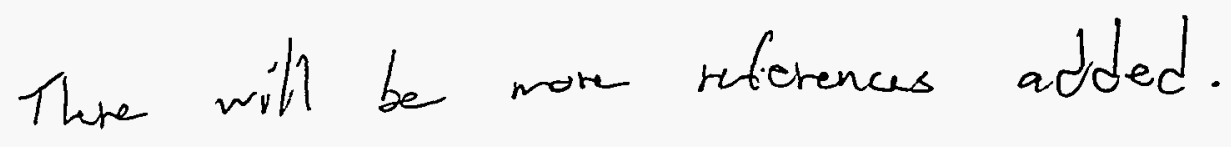

